\title{
Enhancing Healthcare Access-Smartphone Apps in Arrhythmia Screening: Viewpoint
}

Marcin Książczyk ${ }^{1,2}$, MD; Agnieszka Dębska-Kozłowska ${ }^{1}, \mathrm{MD}$, PhD; Izabela Warchoł ${ }^{1}$, MD; Andrzej Lubiński ${ }^{1}$, MD, Prof Dr

${ }^{1}$ Department of Interventional Cardiology and Cardiac Arrhythmias, Medical University of Lodz, Łódź, Poland

${ }^{2}$ Department of Noninvasive Cardiology, Medical University of Lodz, Łódź, Poland

Corresponding Author:

Marcin Książczyk, MD

Department of Interventional Cardiology and Cardiac Arrhythmias

Medical University of Lodz

Ul. Żeromskiego 113

Łódź, 90-549

Poland

Phone: 48426393563

Email: marcin ksiazczyk@interia.pl

\begin{abstract}
Atrial fibrillation is the most commonly reported arrhythmia and, if undiagnosed or untreated, may lead to thromboembolic events. It is therefore desirable to provide screening to patients in order to detect atrial arrhythmias. Specific mobile apps and accessory devices, such as smartphones and smartwatches, may play a significant role in monitoring heart rhythm in populations at high risk of arrhythmia. These apps are becoming increasingly common among patients and professionals as a part of mobile health. The rapid development of mobile health solutions may revolutionize approaches to arrhythmia screening. In this viewpoint paper, we assess the availability of smartphone and smartwatch apps and evaluate their efficacy for monitoring heart rhythm and arrhythmia detection. The findings obtained so far suggest they are on the right track to improving the efficacy of early detection of atrial fibrillation, thus lowering the risk of stroke and reducing the economic burden placed on public health.
\end{abstract}

(JMIR Mhealth Uhealth 2021;9(8):e23425) doi: 10.2196/23425

\section{KEYWORDS}

arrhythmia screening; atrial fibrillation; mobile electrocardiography; mobile health; phonocardiography; photoplethysmography; seismocardiography; stroke prevention

\section{Introduction}

The most commonly reported arrhythmia is atrial fibrillation (AF) [1]. Its prevalence is still underestimated [2], particularly the asymptomatic form: silent AF. Even so, the prevalence of symptomatic AF is estimated to be $0.12 \%-0.16 \%$ in patients aged $<49$ years, $3.7 \%-4.2 \%$ in patients aged $60-70$ years, and almost $10 \%-17 \%$ in those aged $\geq 80$ years [3]. The most common undiagnosed and untreated $\mathrm{AF}$ complications are thromboembolic events, such as stroke, which occur up to 5.6 times more frequently in AF patients [4]. It is therefore desirable to provide screening to patients in order to detect atrial arrhythmias. Additionally, the European Society of Cardiology (ESC) 2020 ESC Guidelines for the diagnosis and management of $\mathrm{AF}$ recommends opportunistic screening for $\mathrm{AF}$ by pulse taking or electrocardiogram (ECG) rhythm strip in patients above 65 years of age, and systematic ECG screening in patients above 75 years of age or those at high risk of stroke [5]. A problem arises when occasionally performed ECG does not record any arrhythmia, and the patient demonstrates palpitations or even worse symptoms, such as a thromboembolic event. As the prevalence of silent AF is estimated to be $10 \%-25 \%$ in the general population [6] and $30 \%-44 \%$ in older adults [7], it is reasonable to promote active screening for $\mathrm{AF}$ in patients at risk of the disease.

Specific mobile apps and accessory devices, such as smartphones and smartwatches, may play a significant role in monitoring heart rhythm in populations who are at high risk of arrhythmia: almost 2.71 billion smartphones are currently in use [8], and almost 150 million smartwatches are predicted to be in use in $2021[9,10]$. In general, the algorithms used by the apps correctly detect AF; however, if an automatic algorithm improperly classifies a trace as AF, it can then be verified and reclassified by a clinician. 
In this viewpoint paper, we assess the availability of smartphone and smartwatch apps and evaluate their efficacy for monitoring heart rhythm and arrhythmia detection. These apps are becoming increasingly common among patients and professionals as a part of mobile health (mHealth) [11].

\section{Methods of Screening for Arrhythmias and Heart Rhythm Monitoring}

Practically, heart rhythm is typically monitored using continuous and intermittent systems. Continuous systems record the heart rhythm continuously from 24 hours up to 3 years; these show ECG varying in duration or with different numbers of presented leads (Figure 1).

Figure 1. Standard systems of heart rhythm monitoring [12-17]. ECG: electrocardiogram; ILR: implantable loop recorder; MCOT: mobile cardiac outpatient telemetry; PEM: patch electrocardiogram monitoring.

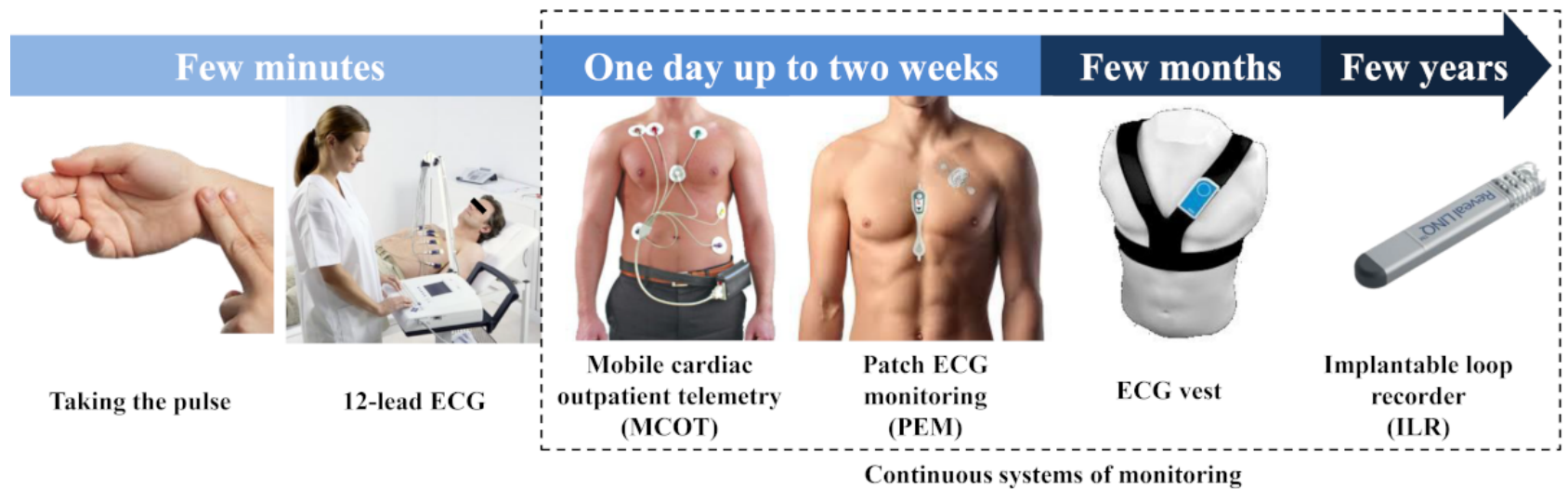

In contrast, intermittent systems are easily accessible and may play a role when continuous monitoring fails or is unacceptable by the patient. They record the heart rhythm on demand and are typically used upon symptom occurrence or according to a routine schedule (ie, each morning). For this paper, intermittent systems are classified into 5 main groups: standalone devices (ie, MyDiagnostick [18], The Heart Check PEN [19], or Lohman Afib Alert [20]), smartphone/smartwatch apps not dependent on an accessory device, smartphone apps dependent on an accessory device, and smartwatch apps.

The apps created for heart rhythm monitoring record the signal by either photoplethysmography (PPG), electrocardiography (ECG), seismocardiography (SCG), or phonocardiography (PCG). Of these, PPGs and ECGs have achieved commercial success. Some apps have been cleared by the United States Food and Drug Administration (FDA) or certified with the Conformite Européenne (CE) mark. They differ regarding their availability for particular mobile operating systems, duration of sample recording, and their ability to detect irregularity or even differentiate AF from normal sinus rhythm or other arrhythmias.

\section{Methods for Identifying Available Apps}

The European (Poland) App Store and Google Play were searched by 2 independent reviewers (MK and IW) for mobile apps that monitor heart rate. The search was performed between the September 9 and September 16, 2019. The apps offered in the App Store were searched using an iPhone 7 Plus with iOS
12.4.1 (Apple Inc), while those offered in Google Play were searched using a Samsung Galaxy S6 (Samsung Electronics) with Android Oreo 8.1 (Google). The following search string was employed: "heart rate" OR "atrial fibrillation" OR "ECG". The inclusion criterion comprised the presence of an analogous or automatic algorithm for arrhythmia detection; no exclusion criteria were applied.

\section{The Overview of Various Technologies and Apps}

A total of 7 Android or iOS accessory device-independent smartphone or smartwatch apps, 8 Android or iOS smartphone accessory device-dependent apps, and 4 Android Wear/watchOS smartwatch apps were identified. An accessory device is defined as a tool with at least 2 built-in electrodes which wirelessly connects to a smartphone and is managed from a dedicated app. In addition to "core" apps that were identifiable in the search (Cardiio Pulsometer, Preventicus Heartbeats, and Kardia Mobile), 4 selected "mother-derived" apps were also evaluated: Cardiio Rhythm, Preventicus Nightwatch (both not available commercially), Kardia Band, and Kardia Mobile 6L. Information about these mother-derived apps are available on the developer's website. Due to the prevalence of ECG-based testing among the apps, 2 ECG-based smartphone apps (Kardia and Istel ECG) and 1 smartwatch app (Health) are presented as representative cases. All identified apps and their characteristics are presented in Tables 1 and 2 . 
Table 1. Characteristics of apps used for heart rhythm monitoring.

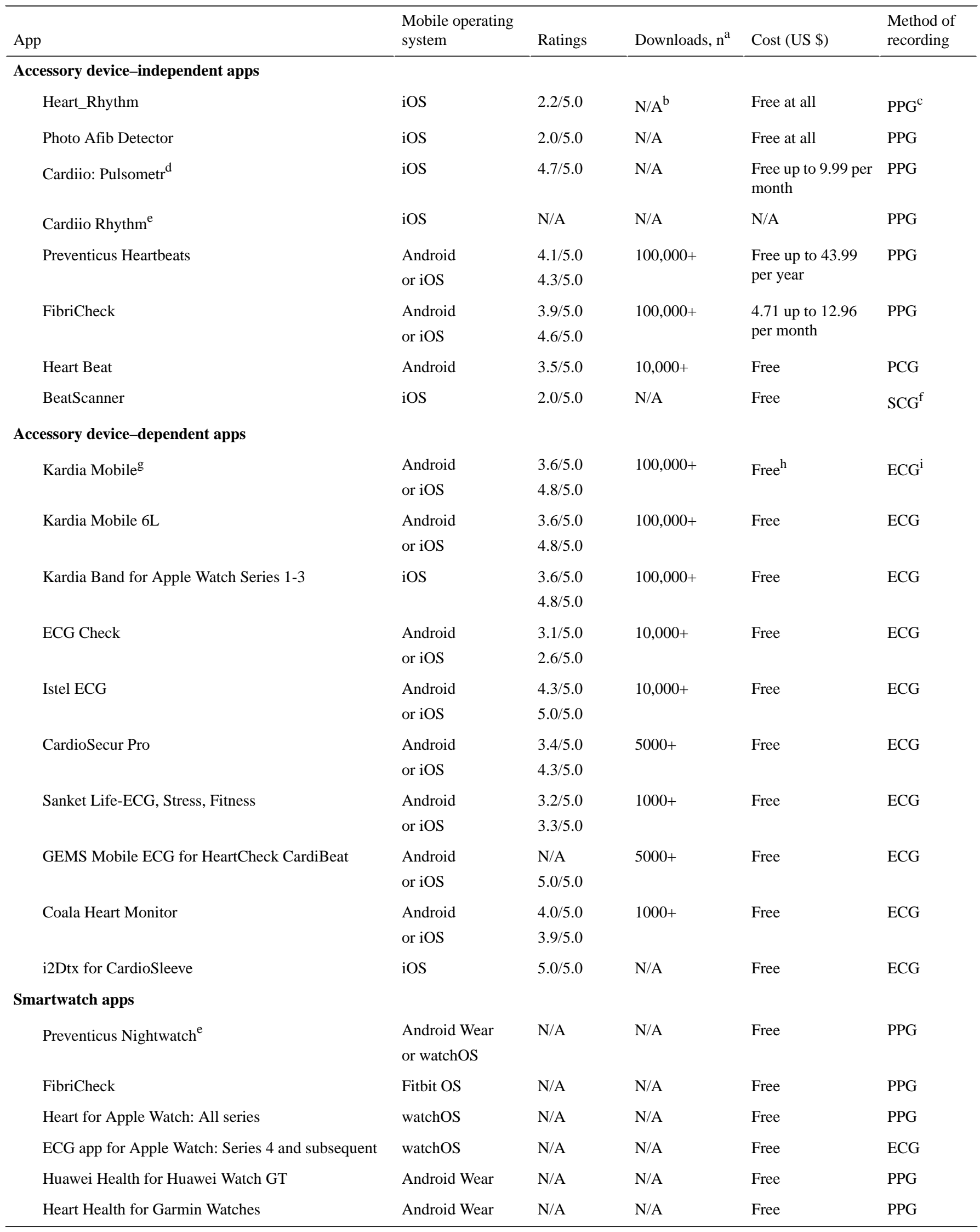

${ }^{\mathrm{a}}$ Data available only for Android apps.

${ }^{\mathrm{b}} \mathrm{N} / \mathrm{A}$ : not applicable.

${ }^{\mathrm{c}} \mathrm{PPG}$ : photoplethysmography.

${ }^{\mathrm{d}}$ Formerly known as Cardiio - Heart Rate. 
${ }^{\mathrm{e}}$ Not available commercially, study version only.

${ }^{\text {f }}$ SCG: seismocardiography.

${ }^{\mathrm{g}}$ Formerly known as AliveCor.

${ }^{\mathrm{h}}$ Device cost not included.

${ }^{\mathrm{i}}$ ECG: electrocardiogram. 
Table 2. Additional characteristics of apps used for heart rhythm monitoring.

\begin{tabular}{|c|c|c|c|c|c|}
\hline App & $\begin{array}{l}\text { Automatic irregularity or } \\
\mathrm{AF}^{\mathrm{a}} \text { detection algorithm }\end{array}$ & FDA $^{\mathrm{b}}$ clearance & $\mathrm{CE}^{\mathrm{c}}$ certificate & Duration of recording & $\begin{array}{l}\text { Number of leads } \\
\text { if applicable }\end{array}$ \\
\hline \multicolumn{6}{|l|}{ Accessory device-independent apps } \\
\hline Heart_Rhythm & No & No & No & $10 \mathrm{~s}$ & $\mathrm{~N} / \mathrm{A}^{\mathrm{d}}$ \\
\hline Photo Afib Detector & Yes & No & No & 30,60, or $120 \mathrm{~s}$ & N/A \\
\hline Cardiio: Pulsometr ${ }^{\mathrm{e}}$ & No & No & No & $20 \mathrm{~s}$ & N/A \\
\hline Cardiio Rhythm ${ }^{\mathrm{f}}$ & Yes & No & No & $20 \mathrm{~s}$ & N/A \\
\hline Preventicus Heartbeats & Yes & No & Ila & 60 or $300 \mathrm{~s}$ & N/A \\
\hline FibriCheck & Yes & Yes & Ila & $60 \mathrm{~s}$ & N/A \\
\hline Heart Beat & No & No & No & $30 \mathrm{~s}$ & N/A \\
\hline BeatScanner & Yes & No & No & $120 \mathrm{~s}$ & N/A \\
\hline \multicolumn{6}{|l|}{ Accessory device-dependent apps } \\
\hline Kardia Mobile ${ }^{\mathrm{g}}$ & Yes & Yes & Ila & $30 \mathrm{~s}$ & 1 \\
\hline Kardia Mobile 6L & Yes & Yes & Ila & $30 \mathrm{~s}$ & 6 \\
\hline $\begin{array}{l}\text { Kardia Band for Apple Watch Series } \\
1-3\end{array}$ & Yes & Yes & Ila & $35 \mathrm{~s}$ & 1 \\
\hline ECG Check & Yes & Yes & Ila & $45 \mathrm{~s}$ & 1 \\
\hline Istel ECG & Yes & No & Ila & $30,60,120$ or $180 \mathrm{~s}$ & 6 \\
\hline CardioSecur Pro & Yes & No & Ila & $30 \mathrm{~s}$ & $6-12$ \\
\hline Sanket Life-ECG, Stress, Fitness & No & No & Ila & $20 \mathrm{~s}$ & 1 \\
\hline $\begin{array}{l}\text { GEMS Mobile ECG for HeartCheck } \\
\text { CardiBeat }\end{array}$ & Yes & Yes & Ila & $30-300 \mathrm{~s}$ & 1 \\
\hline Coala Heart Monitor & Yes & Yes & Ila & $60 \mathrm{~s}$ & 2 \\
\hline i2Dtx for CardioSleeve & Yes & Yes & Ila & $30 \mathrm{~s}$ & 3 \\
\hline \multicolumn{6}{|l|}{ Smartwatch apps } \\
\hline Preventicus Nightwatch ${ }^{\mathrm{f}}$ & Yes & No & Ila & Continuous & N/A \\
\hline FibriCheck & Yes & Yes & Ila & $60 \mathrm{~s}$ & N/A \\
\hline Heart for Apple Watch: All series & No & No & Ila & $\begin{array}{l}\text { Dependent on user activ- } \\
\text { ity }\end{array}$ & N/A \\
\hline $\begin{array}{l}\text { ECG app for Apple Watch: Series } \\
4 \text { and subsequent }\end{array}$ & Yes & Yes & Ila & $30 \mathrm{~s}$ & 1 \\
\hline $\begin{array}{l}\text { Huawei Health for Huawei Watch } \\
\text { GT }\end{array}$ & Yes & No & No & $\begin{array}{l}\text { Dependent on user activ- } \\
\text { ity }\end{array}$ & N/A \\
\hline Heart Health for Garmin Watches & Yes & No & No & $\begin{array}{l}\text { Dependent on user activ- } \\
\text { ity }\end{array}$ & N/A \\
\hline
\end{tabular}

${ }^{\mathrm{a}} \mathrm{AF}$ : atrial fibrillation.

${ }^{b}$ FDA: Food and Drug Administration.

${ }^{\mathrm{c}} \mathrm{CE}$ : Conformité Européenne.

${ }^{\mathrm{d}} \mathrm{N} / \mathrm{A}$ : not applicable.

${ }^{\mathrm{e}}$ Formerly known as Cardiio - Heart Rate.

${ }^{\mathrm{f}}$ Not available commercially, study version only.

${ }^{\mathrm{g}}$ Formerly known as AliveCor.

\section{Apps Using PPG}

PPG is a technology in which a light source, such as an light-emitting diode, illuminates a tissue, and a photodetector measures the amount of backscattered light returned [21]. The amount of backscattered light corresponds with the variations of blood volume over the sampling area. As blood volume is synchronous with heartbeat, PPG can accurately show heart 
rate [22]. Nowadays, it is possible to obtain a photoplethysmogram in a patient suffering from cardiovascular disorders using a smartphone flash acting as a source of light and a camera serving as a photodetector (Figure 2A). Such photoplethysmograms are called "reflective", as both the light source and photodetector are on the same side of a fingertip. In contrast, systems where the light source and photodetector are located opposite to each other (Figure 2B and C), such as a pulse oximeter, are called "transmissive" [23]. A typical photoplethysmogram wave is shown in red in Figure 2D: its peaks are slightly delayed in relation to the $\mathrm{R}$ of the QRS complex in a standard electrocardiogram, representing the time the blood needs to fill up the furthest areas of the body.

Figure 2. (A) Measuring heart rate with mobile photoplethysmography. The finger is placed over the camera when the flash is on. (B) Transmissive method of measuring heart rate with PPG (used in pulse oximeters). (C) Reflective method of measuring heart rate with photoplethysmography (used in smartphones or smartwatches). (D) Differences in wave shape and RR to RR shift between photoplethysmogram (red curve) and electrocardiogram (black curve) [23-25]. LED: light-emitting diode; PD: photodetector; RR: the interval between 2 Rs in 1 heart cycle.

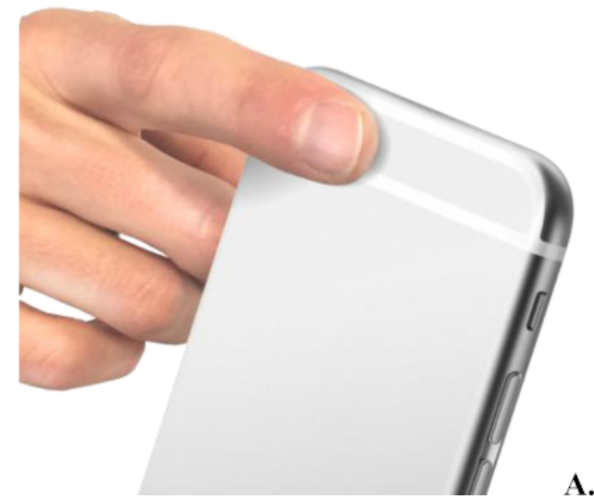

A.

\section{Heart_Rhythm}

Heart_Rhythm is a free app that allows the user to record PPG and then compare the PPG with a model sinus rhythm or atrial fibrillation wave. The efficacy of such subjective self-assessments of rhythm patterns has not been validated in any clinical research [26].

\section{Photo AFib Detector}

Photo Afib Detector is a free app, which automatically detects an abnormality in the pattern of live-recorded PPG signal by estimating 2 statistical parameters: root mean square of successive difference and Shannon entropy [27]. An algorithm combining root mean square of successive difference and Shannon entropy in an iPhone $4 \mathrm{~S}$ showed $96.2 \%$ sensitivity and 97.5\% specificity for beat-to-beat discrimination of AF from sinus rhythm when compared with the 12-lead ECG [28]. However, Photo AFib Detector has not been directly validated in any clinical research.

\section{Cardiio: Pulsometer (Former Name: Cardiio-Heart Rate Monitor) and Cardiio Rhythm}

Cardiio: Pulsometer is a free app, while Cardiio Rhythm is a beta version currently used only for scientific purposes.

Cardiio: Pulsometer records high-quality PPG that can be evaluated by an expert and classified as sinus rhythm or rhythm other than sinus; unfortunately, there is no automatic algorithm for arrhythmia detection. Interestingly, the previous version of Cardiio: Pulsometer, called Cardiio - Heart Rate Monitor, was equipped with a face mode that enabled a contactless measurement of the heart rate based on the face of the user. Although Yan et al [29] showed that both finger and face PPGs demonstrate high accuracy in measuring resting heart rates, the app currently only uses the finger mode due to legal reasons [30].
LED

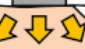

PD

B.

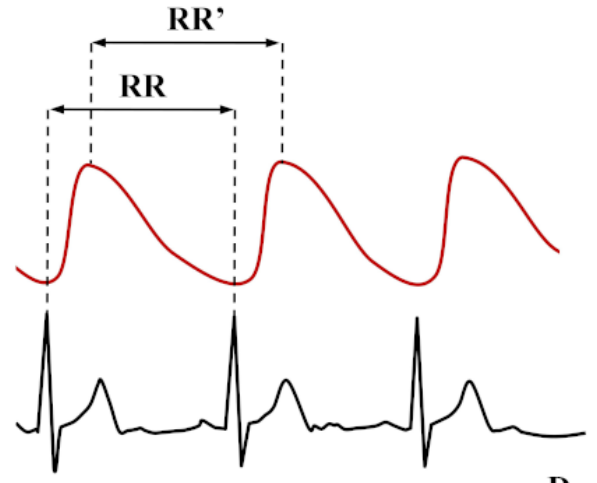

D.

Although Cardiio Rhythm is not currently commercially available, recent clinical findings regarding the app are promising. The sensitivity of the Cardiio Rhythm finger mode (92.9\%, 95\% CI 77-99) was found to be higher than the internet-enabled mobile ECG distributed by AliveCor (iECG; 71.4, 95\% CI 51-87), while Cardiio Rhythm and iECG demonstrated comparable specificity $(97.7 \%, 95 \%$ CI $97-99$ vs 99.4\%, 95\% CI 99-100) [31]. Although Cardiio Rhythm demonstrated a lower positive predictive value (PPV) than did iECG $(53.1 \%, 95 \%$ CI 38-67 vs $76.9 \%, 95 \%$ CI 56-91), both apps had high negative predictive values (NPV; 99.8\%, 95\% CI 99-100 vs 99.2, 95\% CI 98-100) [31]. Cardiio Rhythm finger mode demonstrated $93.1 \%$ sensitivity (95\% CI 86.9-97.2) and 90.9\% specificity (95\% CI 82.9-96.0) compared with superficial ECG, with a 92.2\% PPV (95\% CI 85.8-95.8) and 92.0\% NPV (95\% CI 94.8- 95.9) [32]. Finally, Cardiio Rhythm's facial mode effectiveness demonstrated high sensitivity $(95 \%, 95 \%$ CI $87-98)$ and high specificity (96\%, 95\% CI 91-98) in discriminating AF compared with 12-lead ECG. The PPV and NPV of the facial mode was $92 \%$ (95 CI 84-96) and 97\% (95\% CI 93-99), respectively [33].

\section{Preventicus Heartbeats and Preventicus Nightwatch}

Preventicus Heartbeats is freely available for smartphones, while Preventicus Nightwatch is available only for smartwatch users. Both apps use PPG in screening for AF, and both have been validated in clinical trials.

The full version of Preventicus Heartbeats allows the user to record PPG and receive a complete report about the rhythm variability. In 2019, the Enhanced Diagnostics for Early Detection of Atrial Fibrillation-Prospective Validation (DETECT AF PRO) trial was performed to compare the efficacy of Preventicus Heartbeats in AF screening with iECG. The sensitivity and specificity of the Preventicus Heartbeats app increased with recording time from $1-3$ to 5 minutes: the 
sensitivity was found to be $89.9 \%$ (95\% CI 85.5-93.4), $91.3 \%$ (95\% CI 86.5-94.7), and $91.5 \%$ (95\% CI $85.9-95.4)$, respectively, while the specificity was found to be $99.1 \%(95 \%$ CI 97.5-99.8), 98.7\% (95\% CI 96.7-99.6), and 99.6\% (95\% CI 97.8-100), respectively [34].

A similar trial, Smartwatches for Detection of Atrial Fibrillation (WATCH AF), was carried out to compare the efficacy of heart rhythm monitoring by the Preventicus Nightwatch smartwatch PPG-based algorithm with that of iECG. One-minute recordings were analyzed by the Preventicus Nightwatch (available for smartwatches only) and compared with the iECG. The algorithm demonstrated $93.7 \%$ sensitivity (95\% CI 89.8-96.4) and $98.2 \%$ specificity (95\% CI 95.8- 99.4) in detecting AF $[35,36]$. Preventicus Nightwatch appear to represent a breakthrough in the monitoring of arrhythmia as it will be able to continuously analyze PPG and document AF events lasting for at least 1 minute. However, it still remains in testing [35].

\section{FibriCheck}

Fibricheck is the only PPG-based heart rhythm monitoring app cleared both by the FDA and CE. In one study, a comparison of heart rate measurements by FibriCheck and 2 other FDA-cleared devices, Nonin oximeter and AliveCor, found a correlation of 0.834 between FibriCheck and Nonin, 0.88 between FibriCheck and AliveCor, and 0.897 between Nonin and AliveCor (no significant difference; $P=.61$ ); in addition, an R-R and peak-to-peak interval correlation of 0.993 was found between FibriCheck and wearable ECG (no significant difference; $P=.92$ ) [37].

FibriCheck was also included in the Real Life Digital Population Screening for Atrial Fibrillation Using only a Smartphone
(DIGITAL AF II) study, including over 60,000 participants who completed the monitoring period. The study yielded a database of nearly 600,000 pieces of 1 -minute PPGs [38]. Of these, 791 participants $(1.3 \%)$ presented a trace typical for AF. The prevalence of AF in this population was found to be $1.68 \%$ in patients aged $40-49$ years, $2.16 \%$ in those aged $50-59$ years, $3.23 \%$ in those aged 60-69 years old, 5.97\% in those aged 70-79 years, and $12.3 \%$ in those aged $\geq 80$ years [38]. Unfortunately, the study has a few limitations: the traces were not compared with any other method, such as iECG or ECG, and only selected data were available. Elsewhere, FibriCheck demonstrated a sensitivity of $96 \%$ and a specificity of $91.1 \%$ compared with 12-lead ECG [39]. Its cost is not refundable from national health funds [40].

\section{Heart for Apple Watch: All Series}

The Heart app is an integral part of iOS and watchOS. All Apple Watch series use PPG to record the heart rate, but only series 4 and above are able to record ECG (see section ECG App for Apple Watch: Series 4 or Subsequent). However, Preventicus Nightwatch will be able to use a built-in algorithm to analyze the PPG traces recorded by Apple Watch to detect AF.

\section{Apps Using Electrocardiography (Dependent on an Accessory Device)}

Some mobile apps use ECG for recording and analyzing the signal and are dependent on accessory devices. These devices contain electrodes, whose number and location depend on whether 1-lead or 6-lead ECG is recorded. The devices examined in this paper are displayed in Figure 3, with the total number of the electrodes and recording leads shown in parentheses. 
Figure 3. (A) Kardia Mobile (2 electrodes, 1-lead electrocardiogram). (B) Kardia Mobile 6L (3 electrodes, 6-lead electrocardiogram). (C) Kardia Band (2 electrodes, 1-lead electrocardiogram). (D) ECG Check (2 electrodes, 1-lead electrocardiogram). (E) Istel HR-2000 (4 electrodes, 6-lead electrocardiogram). (F) CardioSecur Pro (4 electrodes, 6-12-lead electrocardiogram). (G) Sanket Life-ECG, Stress, Fitness (3 electrodes, 1-12-lead electrocardiogram). (H) GEMS Mobile ECG for HeartCheck CardiBeat (2 electrodes, 1-lead electrocardiogram). (I) Coala Heart Monitor (3 electrodes, 2-lead electrocardiogram), J. i2Dtx for CardioSleeve (3 electrodes, 3-leads electrocardiogram). (K) Apple Watch Series 4 (3 electrodes, 1-lead electrocardiogram) [41-51].

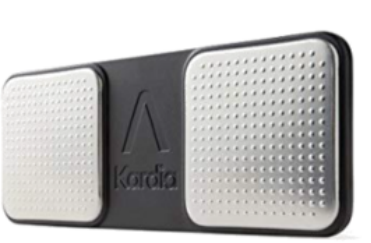

A.

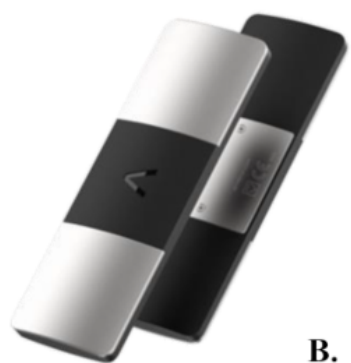

B.
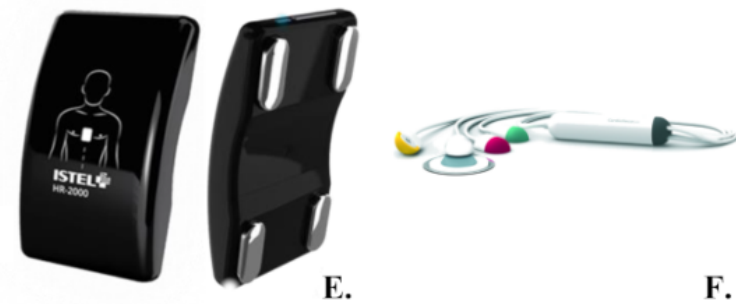
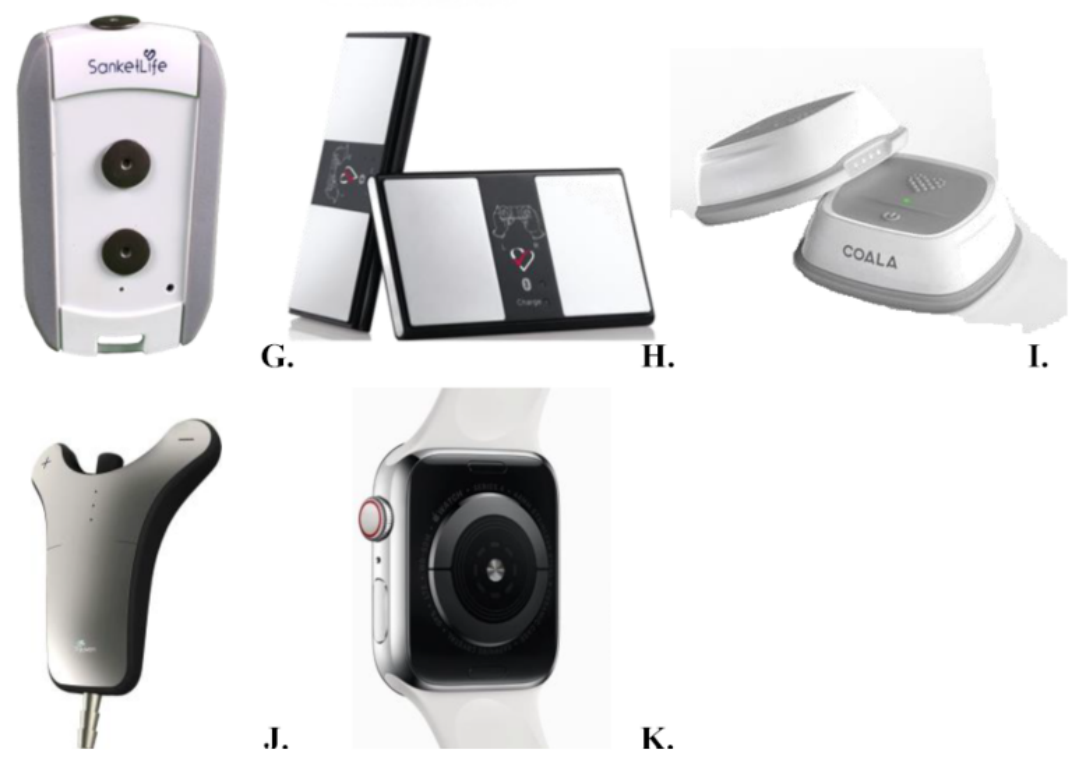

G.

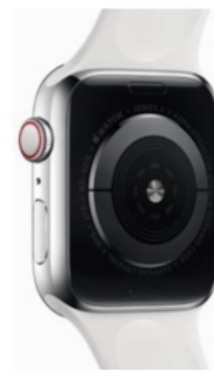

F.

C.

I.

\section{Kardia Mobile}

Kardia Mobile (former name: AliveCor) is a clinically validated mobile device for recording 1-lead ECG and the first to be cleared by the FDA [52]. The first of 2 studies that contributed to FDA clearance of iECG was conducted by Garabelli et al [53]. The obtained ECG curve corresponds to the first (I) limb lead. The Kardia Mobile app has a built-in automatic algorithm for arrhythmia detection focused on AF.

Although some kinds of arrhythmia, like premature ventricular/supraventricular contractions or conduction abnormalities (sinus bradycardia/tachycardia, bundle branch block, or atrioventricular block) may be improperly classified as AF or even unclassified by the automatic algorithm [54,55], the app has been updated to reduce the number of unclassified traces. A study on 214 patients found the single-channel ECG to demonstrate $90.9 \%$ sensitivity (95\% CI 78.3-97.5) and $93.5 \%$ specificity (95\% CI 88.7-96.7) for any rhythm abnormality, and $46.4 \%$ sensitivity (95\% CI $27.5-66.1$ ) and $100 \%$ specificity (95\% CI 98.0-100) for any conduction abnormality [56]. As a result, even if an automatic algorithm improperly classifies the 1-lead ECG trace as AF, it may be correctly reclassified by a clinician.

A comparison of 1-lead ECG with lead I and II of 12-lead ECG in patients taking sotalol or dofetilide found reasonable agreement between measurements of corrected QT (QTc) interval in the sinus rhythm (bias $3 \mathrm{~ms}$; SD of bias $46 \mathrm{~ms}$ ) if QTc <500 ms [57].

The efficacy of Kardia Mobile in arrhythmia detection was validated in patients with cardiovascular implantable electronic devices. A study of recordings from 251 subjects with a pacemaker $(59 \%)$ or implantable cardioverter-defibrillator (41\%) 
in paced and nonpaced states (if possible) found the readings to be adequately interpreted in $90 \%$ of paced recordings ( 25 of 251 recordings were "uninterpretable") and $94.7 \%$ of nonpaced recordings ( 9 of 171 recordings were "uninterpretable") [58].

Kardia Mobile is an effective tool for detecting arrhythmia or conduction abnormalities in children. It was found capable of detecting supraventricular tachycardia, AF, ectopic atrial tachycardia, atrial tachycardia, and ventricular tachycardia, and the users reported a high level of satisfaction [59]. In addition, a relationship was found between QRS dispersion and QTc intervals measured by 1-lead and 12-lead ECG in both healthy children and children with cardiac disease [60].

The QT intervals recorded by Kardia Mobile were $7 \mathrm{~ms}$ shorter than those from the 12-lead ECG, with only a $1.75 \%$ difference. In comparison, PQ intervals were found to be $20 \mathrm{~ms}$ shorter than those of conventional ECG, representing a more than $10 \%$ difference. Such a significant discrepancy between PQ intervals might lead to mimicking arrhythmias, otherwise known as pre-excitation syndrome [61].

\section{Kardia Mobile $6 L$}

The Kardia Mobile 6L is the first FDA-cleared 6-lead ECG. It has 3 built-in electrodes that record 6-lead ECG in channels I-III, aVR, aVL, and aVF [62]. The system uses the same app as the 1-lead Kardia Mobile. Thus far, it has not been included in clinical trials. It is expected that the new $6 \mathrm{~L}$ will provide better-quality ECGs and greater information on ST-segment changes or axis determination than the standard AliveCor device.

\section{Kardia Band}

Kardia Band was the first FDA-cleared medical accessory for the Apple Watch Series 1 to 3 and replaced the original band. It has a specially designed band with 2 built-in side electrodes for recording 1-lead ECG [63]. The sale of Kardia Band was terminated after the Apple Watch Series 4 was released.

\section{Istel HR-2000 (Istel ECG)}

Istel HR-2000 (Diagnosis SA) is a CE-certified device that has 4 built-in electrodes corresponding to 5 electrodes of a conventional ECG: the left arm, right arm, left leg, and right leg. The system records a 6-lead real-time ECG and an automatic algorithm recognizes AF. High-quality reports might be analyzed by experts if the result is ambiguous. The 6-lead ECG might serve as an event recorder, thus allowing the identification of other types of arrhythmia, like supraventricular or ventricular tachycardia, premature ventricular or supraventricular contractions, and atrioventricular blocks [64]. No specificity or sensitivity values for AF detection or the correlation status between intervals measured by the device and conventional ECG has been validated in clinical trials.

\section{ECG App for Apple Watch: Series 4 or Subsequent}

In 2018, Apple Incorporated introduced the Apple Watch Series 4 , the first smartwatch to record a 1-lead ECG, corresponding with lead I from conventional ECG. Apple Watch Series 4 included 2 black crystal electrodes on the back and another electrode that serves as a Digital Crown [65]. An Apple-sponsored multicenter study with 588 patients was performed to determine the Health app's ability to generate an ECG curve corresponding to lead I from a conventional ECG and to use an algorithm classifying heart rhythms as either a sinus rhythm or AF [66]. The results were quite promising: the sensitivity for AF detection was $98.3 \%$ and the specificity was 99.6\%. Consequently, the app was awarded FDA approval for Apple Watch Series 4 and above [66].

One registered clinical trial in the Cleveland Clinic has compared to the Apple Watch Series 4 and standard telemetry monitoring [67]. Recruitment has finished, but the publication of results is still pending.

\section{Other Technologies}

\section{An App Using Phonocardiography: Heart Beat}

Heart Beat is a free app that records heart rate using PCG [68]. PCG is a diagnostic technique that records cardiac acoustic phenomena [69] generated by interactions between the blood flow and heart chambers, valves, and great vessels [70]. A microphone must be placed on the chest to correctly measure the heart rate, with the surroundings remaining in absolute silence. The Heart Beat transforms the audio signal into heartbeat frequency [71]. Heart Beat has a few limitations: it has not been used in any clinical trials, absolute silence is needed when recording the signal, and its status for arrhythmia detection still remains unknown. Due to these limitations, the PCG app cannot be recommended for arrhythmia screening.

\section{An App Using Seismocardiography: BeatScanner}

BeatScanner is the only app that uses SCG [72]. The app uses a very sensitive built-in accelerometer and gyroscope sensors in the smartphone to acquire microvibrations of the precordial area in reaction to heartbeats, blood flow, and respiration $[73,74]$. The vibrations can be studied along the superior-inferior axis (head to foot), the sinister-dexter axis (left to right), and the dorsoventral axis (back to front) [75]. The typical signal received by the gyroscope or accelerometer is called a seismocardiogram. The peaks in the seismocardiogram correspond to the opening and closing of the mitral and aortic valve $[74,76]$. The averaged SCG signal corresponds to ECG (Figure 4) [72,74,76]. According to Salerno and Zanetti [77], SCG might be applied to monitor the function of the left ventricle during ischemia. Paukkunen et al [78] propose that SCG may play a role in detecting atrial flutter. SCG may prove to be useful in arrhythmia detection, as the sensors are built into devices such as smartphones, and the method is noninvasive. Moreover, the sensors are cheap to develop, and the obtained signal is of high quality [75]. Unfortunately, no randomized controlled trials have compared BeatScanner with any of the methods validated for arrhythmia detection. 
Figure 4. (A) The method of testing the seismocardiographic signal by smartphone (user in a reclined position or lying down). (B)_A raw seismocardiogram of a normal sinus rhythm presented in the tab "Signal representation" of the BeatScanner app [72]. (C) Correspondence between the averaged seismocardiogram (red curve) and electrocardiogram (black curve); MC describes the main peaks of seismocardiogram signal. Adapted from adapted from Shafiq et al [74]. MC: mitral valve closing; AO: aortic valve opening; AC: aortic valve closing; MO: mitral valve opening.

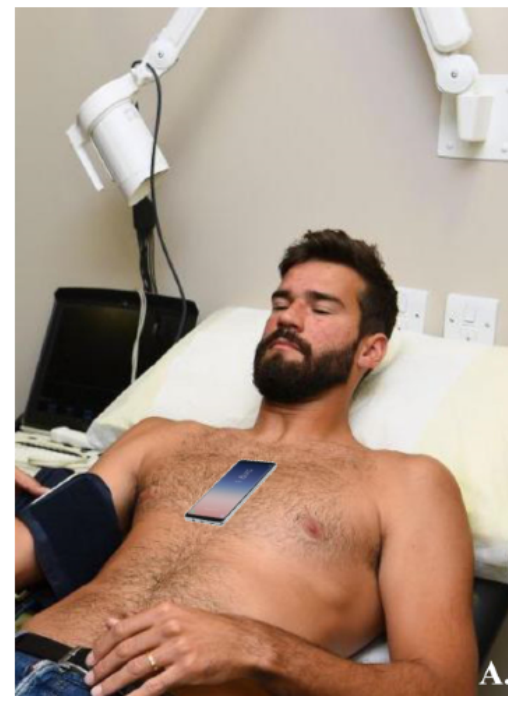

\section{Current Status and Future of Smartphone Apps in Mobile Health}

A number of clinical trials have demonstrated that mobile apps both with and without accessory devices can play a valuable role in arrhythmia screening and that this role may grow in the future. The list of trials given in Table 3 includes those regarding

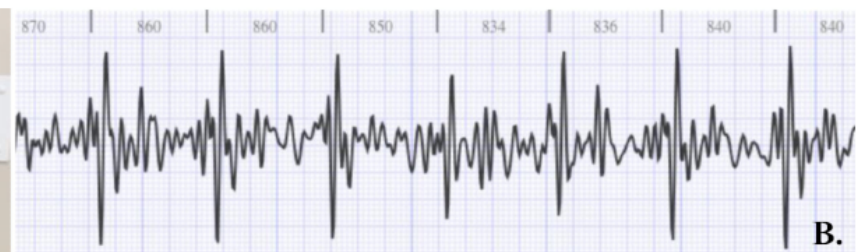

B.

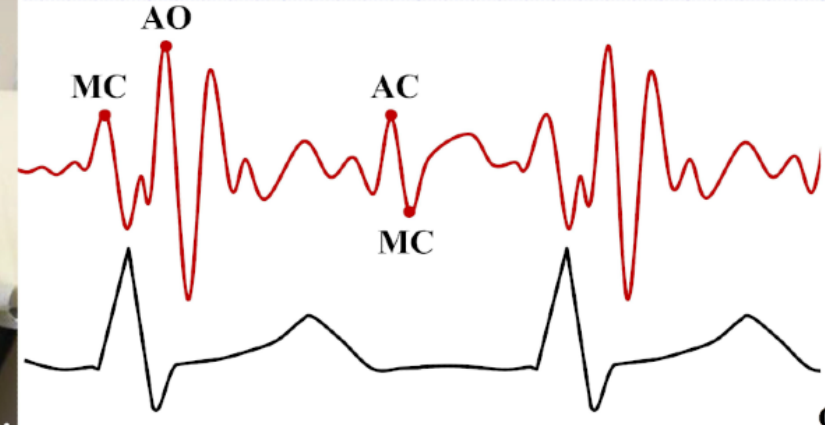

C.

the sensitivity and specificity of the apps and were published in PubMed before June 2020; these studies were identified by a search using the name of the app or name of technology. Some of the apps were evaluated individually (ie, FibriCheck in the DIGITAL AF II at the screening phase) so that the specificity or sensitivity is not available. Others were compared to each other or the gold standard (ie, conventional 12-lead ECG; Table $3)$. 
Table 3. Mobile app in clinical research, including their sensitivity and specificity in detecting atrial fibrillation for individual applications

\begin{tabular}{|c|c|c|c|}
\hline Study by app examined & Method with which the app was compared & Sensitivity $(\%)$ & Specificity $(\%)$ \\
\hline \multicolumn{4}{|l|}{ Smartphone apps } \\
\hline \multicolumn{4}{|l|}{ Photo Afib Detector } \\
\hline Krivoshei et al, 2017 [79] & 12-lead ECG ${ }^{\mathrm{a}}$ & 87.5 & 95.0 \\
\hline McManus et al, 2013 [28] & 12-lead ECG & 96.2 & 97.5 \\
\hline \multicolumn{4}{|l|}{ Cardiio Rhythm ${ }^{b}$} \\
\hline Rozen et al, 2018 [32] & 12-lead ECG & 93.1 & 90.9 \\
\hline Yan et al, 2018 [33] & 12-lead ECG & 95.0 & 96.0 \\
\hline Chan et al, 2016 [31] & AliveCor & 92.9 & 97.7 \\
\hline \multicolumn{4}{|l|}{ Preventicus Heartbeats } \\
\hline Brasier et al (DETECT AF PRO $\left.{ }^{c}\right), 2019$ [34] & AliveCor & $89.9 / 91.3 / 91.5^{\mathrm{d}}$ & $99.1 / 98.7 / 99.6^{\mathrm{d}}$ \\
\hline \multicolumn{4}{|l|}{ FibriCheck } \\
\hline Proesmans et al, 2019 [39] & 12-lead ECG & 96.0 & 91.1 \\
\hline Verbrugge et al, DIGITAL AF II ${ }^{\mathrm{e}}, 2019$ [38] & $N / A^{f}$ & N/A & N/A \\
\hline \multicolumn{4}{|l|}{ Kardia Mobileg } \\
\hline Selder et al, 2019 [54] & 12-lead ECG & 92.0 & 95.0 \\
\hline Koltowski et al, 2019 [61] & 12-lead ECG & 92.8 & 100.0 \\
\hline Himmelreich et al, 2019 [56] & 12-lead ECG & 87.0 & 97.9 \\
\hline Brasier et al (DETECT AF PRO), 2019 [34] & Preventicus Heartbeats & 99.6 & 97.8 \\
\hline William et al. (iREAD $\left.{ }^{\mathrm{h}}\right), 2018$ [80] & 12-lead ECG & 96.6 & 94.1 \\
\hline Lown et al (SAFETY $\left.{ }^{\mathrm{i}}\right), 2018$ [81] & 12-lead ECG & 97.8 & 98.8 \\
\hline Chan et al, 2016 [31] & Cardiio Rhythm & 71.4 & 99.4 \\
\hline Lowres et al (SEARCH-AF), 2014 [82] & 12-lead ECG & 98.5 & 91.4 \\
\hline \multicolumn{4}{|l|}{ Smartwatch apps } \\
\hline \multicolumn{4}{|l|}{ Preventicus Nightwatch } \\
\hline Dörr et al, (WATCH AFj), 2019 [36] & AliveCor & 93.7 & 98.2 \\
\hline \multicolumn{4}{|l|}{ Kardia Band } \\
\hline Wasserlauf et al, 2019 [83] & Reveal LINQ & 97.5 & N/A \\
\hline Bumgarner et al, 2018 [84] & 12-lead ECG & 93.0 & 84.0 \\
\hline \multicolumn{4}{|l|}{ Health for Apple Watch Series 4} \\
\hline Apple Incorporated, 2018 [85] & 12-lead ECG & 98.3 & 99.6 \\
\hline
\end{tabular}

${ }^{\mathrm{a} E C G}$ : electrocardiogram.

${ }^{\mathrm{b}}$ Beta version not commercially available.

${ }^{c}$ DETECT AF PRO: Enhanced Diagnostics for Early Detection of Atrial Fibrillation-Prospective Validation

${ }^{\mathrm{d}}$ Sensitivity and specificity values increased in the course of recording time from 1-3 to 5 minutes.

${ }^{\mathrm{e}}$ DIGITAL AF II: Impact of Smartphone-Based Atrial Fibrillation Screening in the General Population for Primary Stroke Prevention.

${ }^{\mathrm{N}} \mathrm{N} / \mathrm{A}$ : not available.

${ }^{\mathrm{g}}$ Formerly known as AliveCor.

hiREAD: Assessing the Accuracy of an Automated Atrial Fibrillation Detection Algorithm Using Smartphone Technology.

${ }^{i}$ SAFETY: Screening for Atrial Fibrillation Using Economical and Accurate Technology.

${ }^{\mathrm{j}}$ WATCH-AF: Smartwatches for Detection of Atrial Fibrillation.

Smartphone or smartwatch apps appear easy to use and are They may serve as noninvasive event recorders in patients with characterized by high accuracy in arrhythmia detection [86]. unexplained palpitations or presyncope [87]. In addition, heart 
rhythm monitoring based on AliveCor was well received among the pediatric population compared to conventional telemetry devices [59]. As mHealth components, mobile apps can be effectively used to detect the first episode or early recurrence of atrial arrhythmia in patients with high stroke risk and unknown AF [88] or following ablation or cardioversion [89]. Finally, screening for AF with mobile apps can lower the risk of stroke and reduce the economic burden: its use has a good cost-effectiveness ratio $[82,86]$.

The two leading methods of arrhythmia screening are PPG and iECG, with the former being more accessible. Although PPG still needs further investigation, the results of The Huawei Heart Study [90] and The Apple Heart Study [85], conducted on 187,912 and 419,093 participants respectively, seem promising. The findings indicate that PPG may play a significant role in AF screening by detecting heart rhythm irregularity. Regarding the iECG method, European Heart Rhythm Association findings suggest that clinicians' interpretation of arrhythmia episodes detected by apps does not need to be confirmed with ECG before treatment initiation [91]. Apps based on PCG or SCG face a number of hurdles before implementation due to the substantial interference between chest sounds (in PCG) or oscillations (in SCG) with ambient sound or body tremors, the need for direct access to the chest, the need for complete contact between the phone and the chest wall, and the need for of a compulsory position to perform the measurement. These technical details make PCG or SCG less useful than iECG or PPG in everyday practice. In addition, no PCG or SCG apps have been evaluated thus far in clinical trials.

A combination of technologies, such as PPG with subsets of artificial intelligence, is changing health outcomes worldwide. A summary of normal sinus rhythm and AF reports generated by selected apps is shown in Figure 5 . 
Figure 5. Summary of normal sinus rhythm and atrial fibrillation reports, generated by selected apps with detection of irregularity, if applicable.

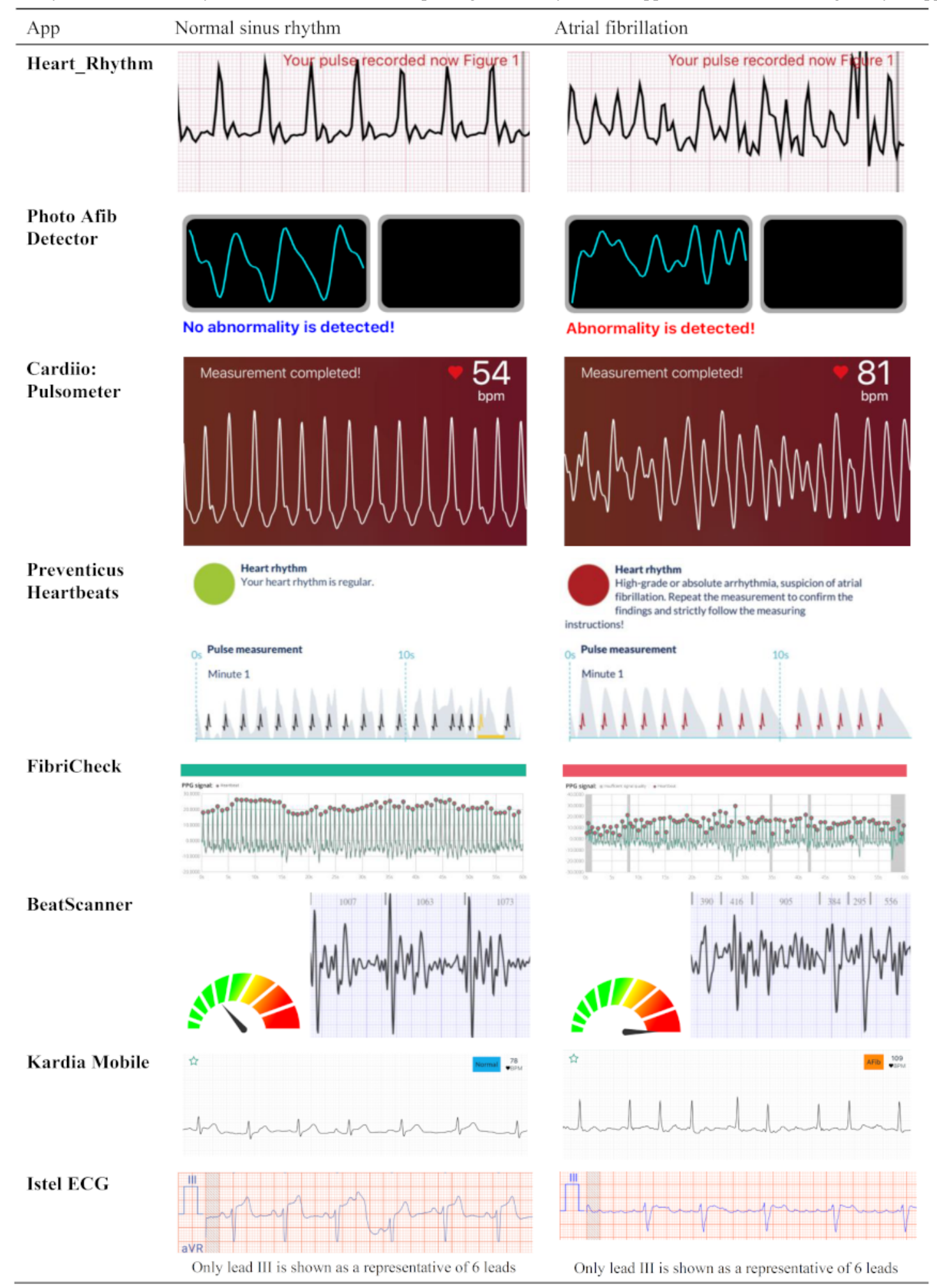

The role of apps supporting AF diagnosis and treatment will doubtlessly grow [90]. Since the first publication regarding the possibility of using PPG in AF detection (McManus et al [28] in 2013), its role has been developed and consolidated. Nowadays, PPG devices are not only used to confirm heart rate or check its regularity, but they can also record real-time iECG and serve as an indication for a specialist to initiate treatment [88]. The apps help detect the first episode of AF, monitor the heart rhythm in paroxysmal AF, monitor the heart rate in permanent $\mathrm{AF}$, and connect the symptom with other arrhythmias or conduction abnormalities [92].

During the 2019 COVID-19 pandemic, when face-to-face consultations were transformed into teleconsultations, the value of smartphone apps and mHealth solutions in remote arrhythmia management was confirmed [93]. With the pandemic gathering pace, mobile apps will undoubtedly become a more fixed part of health infrastructure. 
In addition to arrhythmia screening, some apps can be used for other applications. The literature has discussed the potential for detecting real-time myocardial ischemia using single-lead Kardia Mobile [94] or even ST-elevated myocardial infarction of the inferior wall by transforming single-lead Apple Watch Series 4 into a triple-lead smartwatch [95]. Also, the newly introduced Kardia Mobile 6L seems to be a perfect device for diagnosing myocardial ischemia and even myocardial infarction of the inferior wall, owing to its 6-lead ECG feature [62]. In addition, Yasin et al [96] found that an iECG signal could be processed to calculate the serum potassium concentration in patients undergoing hemodialysis.

\section{Conclusions}

The rapid development of mHealth solutions may revolutionize approaches to arrhythmia screening. The ECG- and PPG-based apps demonstrate greater availability and efficacy in AF detection than those using PCG or SCG.

ECG apps can be used to detect AF; in addition, the results can also be used to precisely diagnose other types of arrhythmias (narrow or wide QRS complex tachycardia, premature supraventricular or ventricular contractions), conduction abnormalities (atrioventricular blocks, intraventricular blocks of undetermined origin), and pathological intervals (short or long QT) if the ECG trace is interpreted by a specialist. In contrast, PPG apps can be used to detect AF or to diagnose general tachycardia or bradycardia of undetermined etiology or premature contractions of undetermined origin. Therefore, it is recommended that PPG apps be used for monitoring treatment efficacy and that ECG apps be used for determining a diagnosis of AF, as robust traces are essential to starting proper treatments, such as those that included oral anticoagulants. However, due to technical details and lack of evidence, PCG or SCG apps cannot be recommended for setting a diagnosis of $\mathrm{AF}$ or for monitoring treatment efficacy.

As new technologies are still being developed, clinical trials of mobile apps in health care are ongoing. The findings obtained so far suggest they are on the right track to improving the efficacy of early detection of AF, thus lowering the risk of stroke and reducing the economic burden placed on public health.

\section{Acknowledgments}

None declared.

\section{Conflicts of Interest}

None declared.

\section{References}

1. Wyndham CR. Atrial fibrillation: the most common arrhythmia. Tex Heart Inst J 2000;27(3):257-267 [FREE Full text] [Medline: 11093410$]$

2. Fitzmaurice DA, Hobbs FDR, Jowett S, Mant J, Murray ET, Holder R, et al. Screening versus routine practice in detection of atrial fibrillation in patients aged 65 or over: cluster randomised controlled trial. BMJ 2007 Aug 25;335(7616):383 [FREE Full text] [doi: 10.1136/bmj.39280.660567.55] [Medline: 17673732 ]

3. Zoni-Berisso M, Lercari F, Carazza T, Domenicucci S. Epidemiology of atrial fibrillation: European perspective. Clin Epidemiol 2014;6:213-220 [FREE Full text] [doi: 10.2147/CLEP.S47385] [Medline: 24966695]

4. Wolf PA, Dawber TR, Thomas HE, Kannel WB. Epidemiologic assessment of chronic atrial fibrillation and risk of stroke: the Framingham study. Neurology 1978 Oct;28(10):973-977. [doi: 10.1212/wnl.28.10.973] [Medline: 570666]

5. Hindricks G, Potpara T, Dagres N, Arbelo E, Bax JJ, Blomström-Lundqvist C, ESC Scientific Document Group. 2020 ESC Guidelines for the diagnosis and management of atrial fibrillation developed in collaboration with the European Association for Cardio-Thoracic Surgery (EACTS): The Task Force for the diagnosis and management of atrial fibrillation of the European Society of Cardiology (ESC) Developed with the special contribution of the European Heart Rhythm Association (EHRA) of the ESC. Eur Heart J 2021 Feb 01;42(5):373-498. [doi: 10.1093/eurheartj/ehaa612] [Medline: 32860505]

6. Rho RW, Page RL. Asymptomatic atrial fibrillation. Prog Cardiovasc Dis 2005;48(2):79-87. [doi: 10.1016/j.pcad.2005.06.005] [Medline: 16253649]

7. Blackshear JL, Safford RE. Immediate and long-term prevention of thromboembolism in atrial fibrillation. Cardiac Electrophysiol Review 1999;3:88-92. [doi: 10.1023/A:1009949007486]

8. O'Dea S. Number of smartphone users worldwide from 2016 to 2021 (in billions). Statista. URL: https://www.statista.com/ statistics/330695/number-of-smartphone-users-worldwide [accessed 2021-03-15]

9. Vailshery LS. Number of connected wearable devices worldwide from 2016 to 2022. Statista. URL: https://www.statista.com/ statistics/487291/global-connected-wearable-devices/ [accessed 2021-03-15]

10. Big data and wearable health monitors: harnessing the benefits and overcoming challenges. Health Informatics. 2019 Sep 17. URL: https://healthinformatics.uic.edu/blog/ big-data-and-wearable-health-monitors-harnessing-the-benefits-and-overcoming-challenges/ [accessed 2021-03-15]

11. Shan R, Ding J, Plante TB, Martin SS. Mobile health access and use among individuals with or at risk for cardiovascular disease: 2018 health information national trends survey (hints). J Am Heart Assoc 2019 Dec 17;8(24):e014390 [FREE Full text] [doi: 10.1161/JAHA.119.014390] [Medline: $\underline{31818220]}$ 
12. Pulse. Saga. URL: https://www.saga.co.uk/contentlibrary/saga/publishing/verticals/health-and-wellbeing/exercise-and-fitness/ pulse768x576.jpg [accessed 2019-09-18]

13. Standard systems of heart rhythm monitoring. Mistry Medical Supplies. URL: https://www.mistrymedical.com/graphics/ products/large/d4z7q9.jpg [accessed 2019-09-18]

14. kardio.CLINIC. URL: http://kardio.clinic/wp-content/uploads/2016/04/holter-300x300.jpg [accessed 2019-09-18]

15. Rho R, Vossler M, Blancher S, Poole JE. Comparison of 2 ambulatory patch ECG monitors: The benefit of the P-wave and signal clarity. Am Heart J 2018 Sep;203:109-117. [doi: 10.1016/j.ahj.2018.03.022] [Medline: 30072027]

16. Konka A, Sredniawa B. Nowoczesne metody stosowane u pacjentów w celu przesiewowego wykrywania migotania przedsionków. Medycyna po Dyplomie 2019;28:54-56.

17. Implantable loop recorder insertion. Ruth Kam Heart \& Arrhthmia Clinic. URL: http://www.arrhythmia.com.sg/wp-content/ uploads/2016/07/implantable loop recorder insertion img 01.jpg [accessed 2019-09-21]

18. MyDiagnostick. URL: https://www.mydiagnostick.com [accessed 2019-09-20]

19. The Heart Check. URL: https://www.theheartcheck.com [accessed 2019-09-20]

20. AfibAlert. Lohman Tech. URL: https://www.lohmantech.com [accessed 2019-09-20]

21. Elgendi M. On the analysis of fingertip photoplethysmogram signals. Curr Cardiol Rev 2012 Feb;8(1):14-25 [FREE Full text] [doi: 10.2174/157340312801215782] [Medline: 22845812]

22. Raj R, Jothi S. Estimation of heart rate from photoplethysmographic signal using SVR method. The International Journal of Science \& Technology, Volume, Issue 2014;2(2):50-52.

23. Tamura T, Maeda Y, Sekine M, Yoshida M. Wearable Photoplethysmographic Sensors_Past and Present. Electronics 2014 Apr 23;3(2):282-302. [doi: 10.3390/electronics3020282]

24. Measuring heart rate with mobile photoplethysmography. Squarespace. URL: https://images.squarespace-cdn.com/content/ 5397da1ae4b0c0c130832759/1460100389675-GROLYC8RNTTA536ZDIOV/?format=1000w\&content-type=image\%2Fpng [accessed 2019-09-22]

25. Your heart's health at your fingertips. FibriCheck. URL: https://www.fibricheck.com [accessed 2019-09-22]

26. Heart_Rhythm. Apple App Store. URL: https://apps.apple.com/us/app/heart-rhythm/id772332884 [accessed 2019-09-22]

27. Photo AFib Detector (Lite). Apple App Store. URL: https://apps.apple.com/us/app/photo-afib-detector-free/id1002024668 [accessed 2019-09-22]

28. McManus DD, Lee J, Maitas O, Esa N, Pidikiti R, Carlucci A, et al. A novel application for the detection of an irregular pulse using an iPhone 4S in patients with atrial fibrillation. Heart Rhythm 2013 Mar;10(3):315-319 [FREE Full text] [doi: 10.1016/j.hrthm.2012.12.001] [Medline: 23220686]

29. Yan BP, Chan CK, Li CK, To OT, Lai WH, Tse G, et al. Resting and postexercise heart rate detection from fingertip and facial photoplethysmography using a smartphone camera: a validation study. JMIR Mhealth Uhealth 2017 Mar 13;5(3):e33 [FREE Full text] [doi: 10.2196/mhealth.7275] [Medline: 28288955]

30. Bending Spoons. URL: https://bendingspoons.com/support.html?app=542891434\#5d8091b2fa90cfc74f2c09dc [accessed 2019-09-22]

31. Chan P, Wong C, Poh YC, Pun L, Leung WW, Wong Y, et al. Diagnostic performance of a smartphone-based photoplethysmographic application for atrial fibrillation screening in a primary care setting. J Am Heart Assoc 2016 Jul 21;5(7):e003428 [FREE Full text] [doi: 10.1161/JAHA.116.003428] [Medline: 27444506]

32. Rozen G, Vaid J, Hosseini SM, Kaadan MI, Rafael A, Roka A, et al. Diagnostic accuracy of a novel mobile phone application for the detection and monitoring of atrial fibrillation. Am J Cardiol 2018 May 15;121(10):1187-1191. [doi: 10.1016/j.amjcard.2018.01.035] [Medline: 29525063]

33. Yan BP, Lai WHS, Chan CKY, Chan SC, Chan L, Lam K, et al. Contact-free screening of atrial fibrillation by a smartphone using facial pulsatile photoplethysmographic signals. J Am Heart Assoc 2018 Apr 05;7(8):e [FREE Full text] [doi: 10.1161/JAHA.118.008585] [Medline: 29622592]

34. Brasier N, Raichle CJ, Dörr M, Becke A, Nohturfft V, Weber S, et al. Detection of atrial fibrillation with a smartphone camera: first prospective, international, two-centre, clinical validation study (DETECT AF PRO). Europace 2019 Jan 01;21(1):41-47 [FREE Full text] [doi: 10.1093/europace/euy176] [Medline: 30085018]

35. Preventicus. URL: https://en.preventicus.com/en/news-ehra-late-breaking-science-sessions-atrial-fibrillation-af-can-capturedsmartphone-cameras-smartwatches-95-accuracy/ [accessed 2019-09-25]

36. Dörr M, Nohturfft V, Brasier N, Bosshard E, Djurdjevic A, Gross S, et al. The WATCH AF Trial: SmartWATCHes for Detection of Atrial Fibrillation. JACC Clin Electrophysiol 2019 Feb;5(2):199-208. [doi: 10.1016/j.jacep.2018.10.006] [Medline: 30784691]

37. Vandenberk T, Stans J, Van SG, Pelckmans C, Smeets CJ, Lanssens D, et al. Clinical validation of heart rate apps: mixed-methods evaluation study. JMIR Mhealth Uhealth 2017 Aug 25;5(8):e129 [FREE Full text] [doi: 10.2196/mhealth.7254] [Medline: 28842392]

38. Verbrugge F, Proesmans T, Vijgen J, Mullens W, Rivero-Ayerza M, Van Herendael H, et al. Atrial fibrillation screening with photo-plethysmography through a smartphone camera. Europace 2019 Aug 01;21(8):1167-1175. [doi:

10.1093/europace/euz119] [Medline: 31056678] 
39. Proesmans T, Mortelmans C, Van Haelst R, Verbrugge F, Vandervoort P, Vaes B. Mobile phone-based use of the photoplethysmography technique to detect atrial fibrillation in primary care: diagnostic accuracy study of the fibricheck app. JMIR Mhealth Uhealth 2019 Mar 27;7(3):e12284. [doi: 10.2196/12284] [Medline: $\underline{30916656}$ ]

40. FibriCheck. Apple App Store. URL: https://apps.apple.com/be/app/fibricheck/id1102327473 [accessed 2019-09-22]

41. KardiaMobile phone clip. AliveCor. URL: https://store.alivecor.com/products/kardiamobile-phoneclip [accessed 2019-10-02]

42. KardiaMobile 6L. level. URL: https://leveldesignsf.com/alivecor [accessed 2019-10-02]

43. Ergodesk. URL: https://www.ergodesk.cz/en/products/biofeedback/alivecor-kardia-ecg-band-apple-watch [accessed 2019-10-02]

44. Istel. URL: http://istel.com.pl/rejestrator-ekg/?lang=en [accessed 2019-10-02]

45. Mobile ECG Event Recorder Heart Monitor ECG Check APP for family use. Borsam. URL: http://ecg-borsam-com. sell.everychina.com/p-105202847-mobile-ecg-event-recorder-heart-monitor-ecg-check-app-for-family-use.html [accessed 2019-10-02]

46. PROAlleine. iF Design. URL: https://uploads.ifdesign.de/award_img_247/oex_large/107521_02_rendering_PROalleine. jpg [accessed 2020-09-20]

47. Agatsa. URL: https://www.agatsa.com/wp-content/uploads/2018/07/device.png [accessed 2020-09-20]

48. CardioComm. Mobile Health News. URL: https://www.mobihealthnews.com/sites/default/files/cardiocomm_0.png [accessed 2020-09-20]

49. Cardiology 2.0. URL: https://magazine.cardiology2.com/cardio2/feb2020/coalalife/397672/Coala Pro.960 0 1.jpg [accessed 2020-09-20]

50. Medical Expo. URL: https://img.medicalexpo.com/images me/photo-g/84877-8973365.jpg [accessed 2020-09-20]

51. ECG app for Apple Watch will reportedly launch with watchOS 5.1.2. iDownloadBlog. URL: https://www. idownloadblog.com/2018/11/28/watchos-5-1-2-ecg-app/ [accessed 2019-10-02]

52. AliveCor. KardiaMobile. URL: https://www.alivecor.com/kardiamobile/ [accessed 2019-10-02]

53. Garabelli P, Albert D. Innovation Abstract \# 12-IA-9662-HRS. 2012 Presented at: Heart Rhythm Society's 33rd Annual Scientific Sessions; 2012 May 9-12; Boston, Massachusetts. [doi: 10.1016/s1547-5271(15)00403-8]

54. Selder JL, Breukel L, Blok S, van Rossum AC, Tulevski II, Allaart CP. A mobile one-lead ECG device incorporated in a symptom-driven remote arrhythmia monitoring program. The first 5,982 Hartwacht ECGs. Neth Heart J 2019 Jan;27(1):38-45 [FREE Full text] [doi: 10.1007/s12471-018-1203-4] [Medline: 30523617]

55. Krajsman M, Polinski J, Pawlik K, Tataj E, Parol G, Cacko A. Utility of mobile single-lead ECG device in hospital emergency department. Folia Cardiologica 2018;5:402-406. [doi: 10.5603/fc.2018.0110]

56. Himmelreich JC, Karregat EP, Lucassen WA, van Weert HC, de Groot JR, Handoko ML, et al. Diagnostic accuracy of a smartphone-operated, single-lead electrocardiography device for detection of rhythm and conduction abnormalities in primary care. Ann Fam Med 2019 Sep;17(5):403-411 [FREE Full text] [doi: 10.1370/afm.2438] [Medline: 31501201]

57. Garabelli P, Stavrakis S, Albert M, Koomson E, Parwani P, Chohan J, et al. Comparison of QT interval readings in normal sinus rhythm between a smartphone heart monitor and a 12-lead ECQ for healthy volunteers and inpatients receiving sotalol or dofetilide. J Cardiovasc Electrophysiol 2016 Jul;27(7):827-832. [doi: 10.1111/jce.12976] [Medline: 27027653]

58. Abudan AA, Isath A, Ryan JD, Henrich MJ, Dugan JL, Attia ZI, et al. Safety and compatibility of smart device heart rhythm monitoring in patients with cardiovascular implantable electronic devices. J Cardiovasc Electrophysiol 2019 Sep;30(9):1602-1609. [doi: 10.1111/jce.14024] [Medline: 31190453]

59. Nguyen HH, Van Hare GF, Rudokas M, Bowman T, Silva JNA. SPEAR Trial: Smartphone Pediatric ElectrocARdiogram Trial. PLoS One 2015;10(8):e0136256 [FREE Full text] [doi: 10.1371/journal.pone.0136256] [Medline: 26295569]

60. Gropler MRF, Dalal AS, Van Hare GF, Silva JNA. Can smartphone wireless ECGs be used to accurately assess ECG intervals in pediatrics? A comparison of mobile health monitoring to standard 12-lead ECG. PLoS One 2018;13(9):e0204403 [FREE Full text] [doi: 10.1371/journal.pone.0204403] [Medline: 30260996]

61. Koltowski L, Balsam P, Glowczynska R, Rokicki JK, Peller M, Maksym J, et al. Kardia Mobile applicability in clinical practice: A comparison of Kardia Mobile and standard 12-lead electrocardiogram records in 100 consecutive patients of a tertiary cardiovascular care center. Cardiol J 2021;28(4):543-548 [FREE Full text] [doi: 10.5603/CJ.a2019.0001] [Medline: $\underline{30644079]}$

62. KardiaMobile6L. KardiaMobile. URL: https://www.alivecor.com/kardiamobile61/ [accessed 2019-10-02]

63. Kardia Band by AliveCor instructions for use. KardiaMobile. URL: https://www.alivecor.com/previous-labeling/kb ifu/ 15LB1.3.pdf [accessed 2019-10-02]

64. Istel. URL: http://istel.com.pl/ [accessed 2019-10-05]

65. ECG app for Apple Watch will reportedly launch with watchOS 5.1.2. iDownload Blog. URL: https://www. idownloadblog.com/2018/11/28/watchos-5-1-2-ecg-app/ [accessed 2019-10-05]

66. Apple App store. URL: https://www.apple.com/healthcare/site/docs/Apple_Watch_Arrhythmia_Detection.pdf [accessed 2019-10-05]

67. Gillinov M. Accuracy of the Apple Watch Series 4 for detection of heart rhythm: a pilot study. ClinicalTrials.gov. URL: https://clinicaltrials.gov/ct2/show/NCT03798613?cond=apple+watch+4\&draw=2\&rank=1 [accessed 2019-10-05] 
68. Google Play. URL: https://play.google.com/store/apps/details?id=com.hahoteknik.HeartBeatMaster\&hl=en_US [accessed 2019-09-22]

69. Noponen A, Lukkarinen S, Sepponen R. Section I: current methods and their applications for cardiovascular multimodal imaging. Chapter 2: phonocardiography. In: Pahlm O, Wagner GS, editors. Multimodal Cardiovascular Imaging: Principles and Clinical Applications. New York: The McGraw-Hill Companies; 2011.

70. Tang H, Zhang J, Sun J, Qiu T, Park Y. Phonocardiogram signal compression using sound repetition and vector quantization. Comput Biol Med 2016 Apr 01;71:24-34 [FREE Full text] [doi: 10.1016/j.compbiomed.2016.01.017] [Medline: 26871603]

71. Heart Beat Rate Monitor App. YouTube. URL: https://www.youtube.com/watch?v=9GFThK8Iu0k [accessed 2019-09-22]

72. Features. BeatScanner. URL: https://www.beatscanner.com/\#features [accessed 2019-09-28]

73. Jafari Tadi M, Lehtonen E, Saraste A, Tuominen J, Koskinen J, Teräs M, et al. Gyrocardiography: a new non-invasive monitoring method for the assessment of cardiac mechanics and the estimation of hemodynamic variables. Sci Rep 2017 Jul 28;7(1):6823 [FREE Full text] [doi: 10.1038/s41598-017-07248-y] [Medline: 28754888]

74. Shafiq G, Tatinati S, Ang WT, Veluvolu KC. Automatic identification of systolic time intervals in seismocardiogram. Sci Rep 2016 Nov 22;6:37524 [FREE Full text] [doi: 10.1038/srep37524] [Medline: 27874050]

75. Wahlstrom J, Skog I, Handel P, Khosrow-Khavar F, Tavakolian K, Stein PK, et al. A hidden Markov Model for seismocardiography. IEEE Trans Biomed Eng 2017 Oct;64(10):2361-2372. [doi: 10.1109/TBME.2017.2648741] [Medline: 28092512]

76. Laurin A, Imperiale S, Moireau P, Blaber A, Chapelle D. A 3D model of the thorax for seismocardiography. Computing in Cardiology Conference 2015:465-468. [doi: 10.1109/cic.2015.7408687]

77. Salerno DM, Zanetti J. Seismocardiography for monitoring changes in left ventricular function during ischemia. Chest 1991 Oct;100(4):991-993. [doi: 10.1378/chest.100.4.991] [Medline: 1914618 ]

78. Paukkunen M, Parkkila P, Hurnanen T, Pänkäälä M, Koivisto T, Nieminen T, et al. Beat-by-beat quantification of cardiac cycle events detected from three-dimensional precordial acceleration signals. IEEE J Biomed Health Inform 2016 Mar;20(2):435-439. [doi: 10.1109/JBHI.2015.2391437] [Medline: 25594987]

79. Krivoshei L, Weber S, Burkard T, Maseli A, Brasier N, Kühne M, et al. Smart detection of atrial fibrillation $\dagger$. Europace 2017 May 01;19(5):753-757 [FREE Full text] [doi: 10.1093/europace/euw125] [Medline: 27371660]

80. William AD, Kanbour M, Callahan T, Bhargava M, Varma N, Rickard J, et al. Assessing the accuracy of an automated atrial fibrillation detection algorithm using smartphone technology: The iREAD Study. Heart Rhythm 2018 Oct;15(10):1561-1565. [doi: 10.1016/j.hrthm.2018.06.037] [Medline: 30143448]

81. Lown M, Yue AM, Shah BN, Corbett SJ, Lewith G, Stuart B, et al. Screening for Atrial Fibrillation Using Economical and Accurate Technology (From the SAFETY Study). Am J Cardiol 2018 Oct 15;122(8):1339-1344. [doi: 10.1016/j.amjcard.2018.07.003] [Medline: 30131106]

82. Lowres N, Neubeck L, Salkeld G, Krass I, McLachlan AJ, Redfern J, et al. Feasibility and cost-effectiveness of stroke prevention through community screening for atrial fibrillation using iPhone ECG in pharmacies. The SEARCH-AF study. Thromb Haemost 2014 Jun;111(6):1167-1176. [doi: 10.1160/TH14-03-0231] [Medline: 24687081]

83. Wasserlauf J, You C, Patel R, Valys A, Albert D, Passman R. Smartwatch performance for the detection and quantification of atrial fibrillation. Circ Arrhythm Electrophysiol 2019 Jun;12(6):e006834. [doi: 10.1161/CIRCEP.118.006834] [Medline: 31113234]

84. Bumgarner JM, Lambert CT, Hussein AA, Cantillon DJ, Baranowski B, Wolski K, et al. Smartwatch algorithm for automated detection of atrial fibrillation. J Am Coll Cardiol 2018 May 29;71(21):2381-2388 [FREE Full text] [doi: 10.1016/j.jacc.2018.03.003] [Medline: 29535065]

85. Turakhia MP, Desai M, Hedlin H, Rajmane A, Talati N, Ferris T, et al. Rationale and design of a large-scale, app-based study to identify cardiac arrhythmias using a smartwatch: The Apple Heart Study. Am Heart J 2019 Jan;207:66-75 [FREE Full text] [doi: 10.1016/j.ahj.2018.09.002] [Medline: $\underline{\text { 30392584] }}$

86. Giebel GD, Gissel C. Accuracy of mHealth devices for atrial fibrillation screening: systematic review. JMIR Mhealth Uhealth 2019 Jun 16;7(6):e13641 [FREE Full text] [doi: 10.2196/13641] [Medline: 31199337]

87. Reed MJ, Grubb NR, Lang CC, O'Brien R, Simpson K, Padarenga M, et al. Multi-centre randomised controlled trial of a smart phone-based event recorder alongside standard care versus standard care for patients presenting to the Emergency Department with palpitations and pre-syncope - the IPED (Investigation of Palpitations in the ED) study: study protocol for a randomised controlled trial. Trials 2018 Dec 29;19(1):711 [FREE Full text] [doi: 10.1186/s13063-018-3098-1] [Medline: $\underline{\text { 30594256] }}$

88. Halcox JP, Wareham K, Cardew A, Gilmore M, Barry JP, Phillips C, et al. Assessment of remote heart rhythm sampling using the AliveCor Heart Monitor to screen for atrial fibrillation: The REHEARSE-AF study. Circulation 2017 Nov 07;136(19):1784-1794. [doi: 10.1161/CIRCULATIONAHA.117.030583] [Medline: 28851729]

89. Goldenthal IL, Sciacca RR, Riga T, Bakken S, Baumeister M, Biviano AB, et al. Recurrent atrial fibrillation/flutter detection after ablation or cardioversion using the AliveCor KardiaMobile device: iHEART results. J Cardiovasc Electrophysiol 2019 Nov;30(11):2220-2228 [FREE Full text] [doi: 10.1111/jce.14160] [Medline: 31507001] 
90. Guo Y, Wang H, Zhang H, Liu T, Liang Z, Xia Y, MAFA II Investigators. Mobile photoplethysmographic technology to detect atrial fibrillation. J Am Coll Cardiol 2019 Nov 12;74(19):2365-2375 [FREE Full text] [doi: 10.1016/j.jacc.2019.08.019] [Medline: $\underline{31487545}$ ]

91. Svennberg E, Camm A. Mobile Health as diagnostic or screening tool for arrhythmias: solution or a threat? EHRA webinar. ESC 365. URL: https://esc365.escardio.org/Congress/EHRA-Webinar/EHRA-Webinars-2019/

221278-mobile-health-as-diagnostic-or-screening-tool-for-arrhythmias-solution-or-a-threat [accessed 2019-06-25]

92. Turakhia MP, Kaiser DW. Transforming the care of atrial fibrillation with mobile health. J Interv Card Electrophysiol 2016 Oct;47(1):45-50 [FREE Full text] [doi: 10.1007/s10840-016-0136-3] [Medline: 27306552]

93. Pluymaekers N, Hermans ANL, van der Velden RMJ, den Uijl DW, Vorstermans B, Buskes S, et al. On-demand app-based rate and rhythm monitoring to manage atrial fibrillation through teleconsultations during COVID-19. Int J Cardiol Heart Vasc 2020 Jun;28:100533 [FREE Full text] [doi: 10.1016/j.ijcha.2020.100533] [Medline: 32391412]

94. Joseph J, Redwood S. Mobile digital health devices and the diagnosis in real-time of myocardial ischaemia. QJM 2017 May 01;110(5):309-310 [FREE Full text] [doi: 10.1093/qjmed/hcx046] [Medline: 28339806]

95. Avila CO. Novel use of Apple Watch 4 to obtain 3-lead electrocardiogram and detect cardiac ischemia. Perm J 2019;23:99-102 [FREE Full text] [doi: 10.7812/TPP/19-025] [Medline: 31314734]

96. Yasin OZ, Attia Z, Dillon JJ, DeSimone CV, Sapir Y, Dugan J, et al. Noninvasive blood potassium measurement using signal-processed, single-lead ecg acquired from a handheld smartphone. J Electrocardiol 2017;50(5):620-625 [FREE Full text] [doi: 10.1016/j.jelectrocard.2017.06.008] [Medline: 28641860]

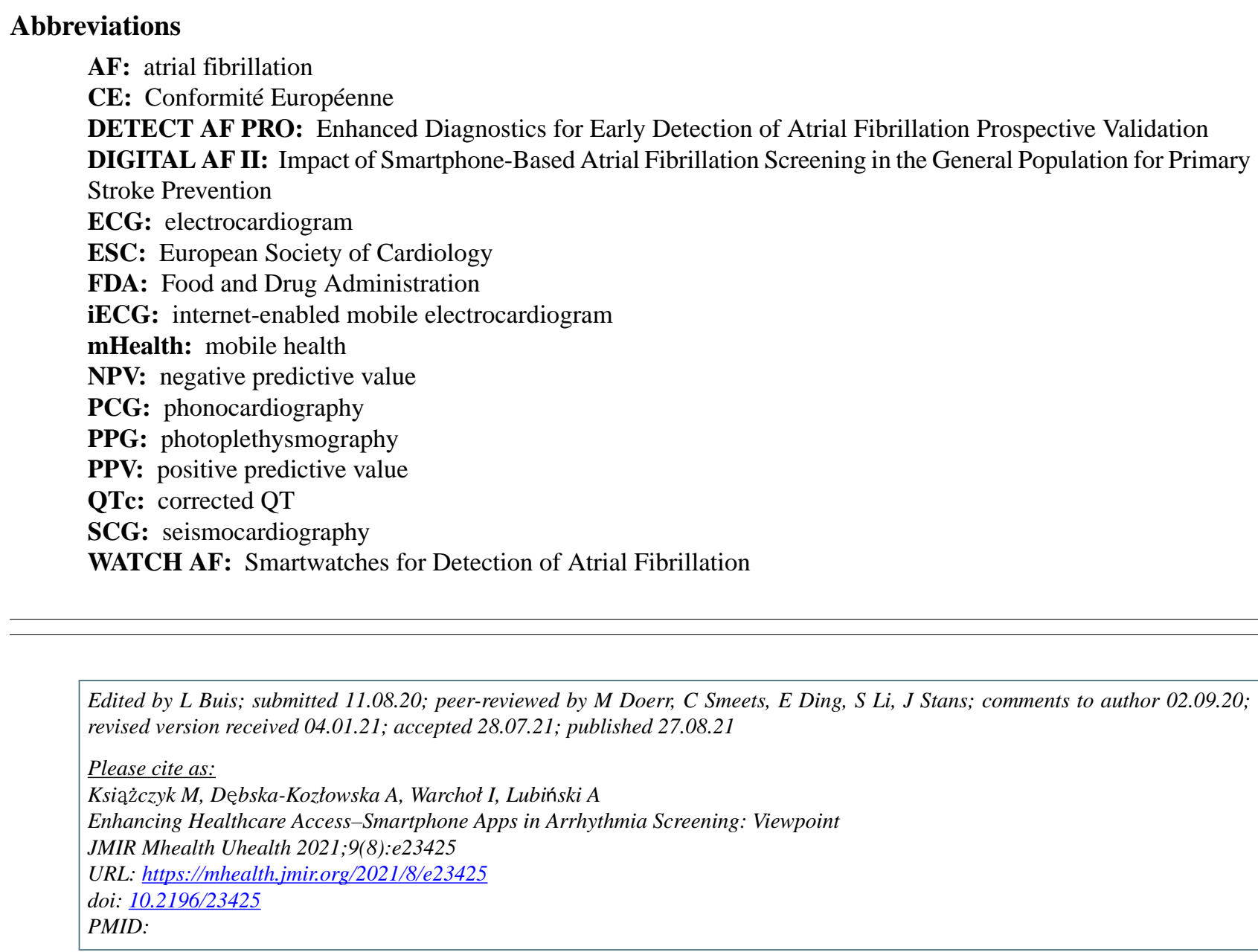

CMarcin Książczyk, Agnieszka Dębska-Kozłowska, Izabela Warchoł, Andrzej Lubiński. Originally published in JMIR mHealth and uHealth (https://mhealth.jmir.org), 27.08.2021. This is an open-access article distributed under the terms of the Creative Commons Attribution License (https://creativecommons.org/licenses/by/4.0/), which permits unrestricted use, distribution, and reproduction in any medium, provided the original work, first published in JMIR mHealth and uHealth, is properly cited. The complete bibliographic information, a link to the original publication on https://mhealth.jmir.org/, as well as this copyright and license information must be included. 